\title{
Entre Francia y España. Conflicto político y defensa hispánica de la frontera en la Cerdaña, 1659-1672*
}

\author{
Antonio Espino López ${ }^{1}$ \\ Universidad Autónoma de Barcelona \\ antonio.espino@uab.cat
}

RESUMEN: El principal objetivo de este trabajo ha sido analizar la constitución de una nueva frontera militar en Cataluña y el papel especifico jugado por la comarca de la Cerdaña, dividida entre las monarquías francesa e hispana desde 1659. Se ha comparado las aportaciones de autores como P. Sahlins y A. Ayats con la documentación exhumada en el Archivo General de Simancas y el Archivo de la Corona de Aragón. Los años que median entre la Paz de los Pirineos y el inicio de la guerra de Holanda nos permiten contextualizar las enormes dificultades tenidas por la Monarquía Hispánica a la hora de desarrollar una política defensiva adecuada en el área, concluyendo que las dificultades económicas lastraron la posibilidad de hacer de Puigcerdà una verdadera fortaleza capaz de representar un peligro real para la corona francesa en el Pirineo.

\section{Palabras Clave: Cerdaña; Francia; Monarquía Hispánica; fronte- ra; defensa; siglo XVII.}

\footnotetext{
* El presente trabajo se ha podido realizar merced a la ayuda concedida por Ministerio de Economía y Competitividad al proyecto: «Conflictos religiosos y conflictos políticobélicos en tierras de frontera. el caso de la nueva frontera catalana, 1635-1789», con referencia HAR2014-57279-P.

AGS, Archivo General de Simancas.

GA, Guerra Antigua.

CG, Consejo de Guerra.

CE, Consejo de Estado.

ACA, Archivo de la Corona de Aragón.

CA, Consejo de Aragón.

ACCE, Archivo Comarcal de la Cerdaña.

1 ORCID iD: http://orcid.org/0000-0003-2856-3035. 
Between France and Spain. Political conflict and defense of the Cerdanya border, 1659-1672

ABSTRACT: The main focus of this study was to analyse the creation of a new military border in Catalonia and the specific role played by the region of Cerdanya, divided between the French and Spanish monarchies since 1659. We compared the contributions of authors like P. Sahlins and A. Ayats with documentation unearthed in the General Archive of Simancas and the Archive of the Crown of Aragon. The years between the Peace of the Pyrenees and the beginning of the war in the Netherlands allow us to contextualize the enormous difficulties faced by the Spanish Monarchy when developing an appropriate defensive policy in the area. We conclude that economic difficulties frustrated attempts to make Puigcerdà fortress a real threat to the French crown in the Pyrenees.

KEY WORDS: Cerdanya; France; Spanish Monarchy; border; defense; seventeenth century.

CÓMO CITAR ESTE ARTÍCULO/CITATION: Espino López, Antonio, «Entre Francia y España. Conflicto político y defensa hispánica de la frontera en la Cerdaña, 16591672», Hispania, 77/257 (Madrid, 2017): 705-733. doi: 103989/hispania.2017.019.

El principal propósito de este artículo es analizar con el mayor rigor posible el papel bélico desempeñado por la comarca de la Cerdaña, y en especial por la plaza de Puigcerdà, en el periodo transcurrido entre la firma de la paz de los Pirineos (1659) y los años previos al inicio de la guerra de Holanda (1673). Son unos años muy trascendentes, pues una nueva frontera (militar), además de política y jurisdiccional, se fue consolidando en aquellas fechas. De hecho, la Cerdaña, dividida entre las monarquías hispánica y francesa, pasó de ser el principal baluarte hispano en el Pirineo merced a la proyección defensiva irradiada desde la plaza de Puigcerdà, que prolongaba la frontera militar $^{2}$ hispana hasta el Conflent, a un territorio de conquista por parte de Francia, especialmente tras la destrucción de la murallas de la villa en 1678. Así, nuestra intención ha sido, pues, establecer las fases evolutivas iniciales (1659-1666; 1667-1672) de lo que podríamos llamar la defensa pirenaica a partir de la experiencia de la Cerdaña, pero sin olvidar ni los territorios más cercanos, tanto a un lado como al otro de la frontera, ni las estrategias de fon-

2 Sobre la cuestión de las fronteras militares en el mundo hispánico, véanse los trabajos de HESS, 1978. PORRAS GIL, 1995. LÁZARO ÁVILA, 1997. ALONSO ACERO, 2000. GOZALBES BUSTO, 2000. WEBER, 2000. USUNÁRIZ, 2007. REICHERT, 2013. MARTÍ y ESPINO, 2013. SÁNCHEZ RUBIO, SÁNCHEZ RUBIO y TESTÓN, 2014. MOREIRA, 2015. ESPINO y JANÉ, 2015. Y sobre las fronteras militares a nivel planetario en la época moderna, BLACK, 2011. 
do que regían las tomas de decisión político-militares tanto de Francia como de la Monarquía de los Habsburgo ${ }^{3}$.

Para desarrollar nuestro empeño las principales fuentes archivísticas consultadas, que no únicas, han sido las pertenecientes al Consejo de Aragón (Archivo de la Corona de Aragón), y a los Consejos de Estado y Guerra (Archivo General de Simancas y Archivo Histórico Nacional). Por otro lado, se han consultado con un cierto detenimiento los fondos del Archivo Comarcal de la Cerdaña. Un historiador, Alain Ayats, realizó en su momento un enorme trabajo de investigación en los archivos militares franceses (SHAT) y en los Archivos Departamentales de los Pirineos Orientales, de modo que tenemos cubierto el periodo 1659-1681 en lo que respecta a las motivaciones galas en estos conflictos. Pero también Òscar Jané Checa ha revisado la documentación francesa de los archivos del país vecino mencionados para la segunda mitad del siglo XVII con una cierta profundidad. Nuestra labor ha consistido, por lo tanto, en contrastar las fuentes hispano-catalanas con las fuentes catalano-francesas analizadas por ambos autores. Es una circunstancia que hasta ahora no se había producido. Alain Ayats no trabajó con fondos hispanos, y su principal fuente de información de la época desde el punto de vista del sur de la frontera fueron los Anales de Catalunya de Narcís Feliu de la Penya (Barcelona, 1709). Òscar Jané analizó algunos, pocos, fondos hispanos, pero el principal problema que podemos detectar en sus diversos trabajos dedicados a la frontera catalana, rigurosos en general, aunque un tanto repetitivos, es una falta de interés real por las cuestiones bélicas, aparte de por vincular las problemáticas del frente catalán en los conflictos hispano-galos de la segunda mitad del siglo XVII con las suscitadas con los otros dos frentes principales donde batallaban ambas monarquías: Flandes y Milán. Alain Ayats sí tiene en cuenta dichas circunstancias, sobre todo en lo que tiene que ver con Flandes, sin duda el frente más importante de los tres hasta 1684, al menos. Sencillamente, no se entiende lo ocurrido en la frontera catalana sin vincularlo con todos los intereses estratégicos de la Monarquía Hispánica, o de la francesa.

Por otro lado, autores como Guy Rowlands o J.-Ph. Cénat ${ }^{4}$, cuyos trabajos examinan la estrategia político-militar del reinado de Luis XIV, mencionan de manera muy restrictiva el frente del Rosellón. Algo parecido ocurre con el conocido análisis sobre los ejércitos de Luis XIV de John Lynn ${ }^{5}$. De la misma manera, tampoco se entienden las decisiones arquitectónico-defensivas que se iban a decidir para aplicar en la Cerdaña si no se entroncan con las tomadas para el resto de los distritos catalanes. En nuestro caso, se ha procurado no

3 Para conocer algunos aspectos, sobre todo el juego político, durante el reinado de Carlos II es imprescindible MAURA GAMAZO, 1990.

4 ROWLANDS, 2002. CÉNAT, 2010.

5 LYNN, 1998. 
perder de vista el conjunto, pero sin olvidar tampoco en demasía el principal objeto, mucho más concreto, de estudio. También es cierto que si bien nos ha interesado la cuestión del binomio identidad-alteridad, y desde los trabajos de Peter Sahlins quedó demostrado que la Cerdaña era un ámbito de investigación perfecto a dicho nivel, no ha sido este el principal objetivo de nuestro análisis, no sólo por las investigaciones desarrolladas por el citado Sahlins, sino también por las de Òscar Jané, que le son muy deudoras, si bien desde un espíritu no exento de algunas críticas (por ejemplo, dándole mucha más importancia a la creación de Montlluís) ${ }^{6}$.

Es más, las páginas dedicadas a los asuntos estrictamente militares por parte de Peter Sahlins en su trabajo sobre la Cerdaña no son demasiadas, aunque correctas. Algo muy parecido ocurre en el caso de Òscar Jané, como se ha señalado. De cualquier manera, en nuestro trabajo desmentiremos una apreciación de P. Sahlins. El historiador norteamericano señaló que «el novell estat modern era una entitat molt distant que interferia rarament en els afers comunals $\rangle^{7}$. ¿Cómo se puede mantener semejante afirmación? Solo si no se tiene en cuenta el fenómeno bélico ${ }^{8}$. El estado moderno interfería absolutamente en todos los asuntos comunales cuando llevaba sus ejércitos, y todo lo que ello implicaba, hasta la frontera catalana, hasta el Pirineo. Cuando alojaba sus tropas en Puigcerdà sin ir más lejos.

\section{AÑos DE INDEFINICIÓN, 1659-1667}

El 4 de junio de 1659 se firmaba en París el tratado preliminar de paz entre las monarquías de España y Francia. El artículo cuarenta y nueve del tratado definitivo (de noviembre de aquel mismo año) especificaba las plazas catalanas ocupadas por los franceses que se retornarían: Rosas y el fuerte de la Trinitat, Cadaqués, Seo de Urgel, Tuixén, el castillo de la Bastida, las villas y plazas de Bagà y Ripoll, así como, del condado de la Cerdaña, los lugares, villas y plazas de la vertiente hispana de los Pirineos: Puigcerdà, Bellver, Querol y la Torre Cerdana. Las plazas de la Cerdaña y Urgel debían ser devueltas a España el 4 de enero de 1660 y las del Ampurdán el 5 de mayo ${ }^{9}$. La

6 JANÉ, 2008. En menor medida, Jané también presta atención a los exiliados políticos: JANÉ, 2010.

7 SAHLINS, 1993: 30.

8 Una crítica al excesivo peso otorgado a los factores político-militares a la hora de establecer las identidades (y las contraidentidades), así como una crítica a la visión política excesivamente localista de la Cerdaña dentro del sistema político general de la Cataluña de la Época Moderna de P. Sahlins, en SERRA, 2010: 345-359.

9 Entre la abundante producción acerca del tratado de los Pirineos y sus consecuencias, véase AYATS, 2002: 94-144. JANÉ, 2006: 102-241. MARCET, 1985. SANABRE, 1956; 1985: 89-104; 1989. VALLADARES, IV/2 (Madrid, 1989): 111-123. 
imprecisión de algunos de los capítulos del tratado obligó a un encuentro en Ceret entre las delegaciones hispana y gala entre el 22 de marzo y el 13 de abril de 1660, que concluyeron sin avances significativos. La situación obligó a una nueva reunión, realizada en el río Bidasoa, entre don Luis de Haro y el cardenal Mazzarino, plenipotenciarios de ambas coronas, cuando se decidió que los condados del Rosellón y Conflent serían franceses, mientras que la Cerdaña sería hispana, salvo treinta y tres lugares del valle de Querol en el Capcir. Con el control del Conflent y del Capcir, Francia se aseguraba el cierre de los accesos al Rosellón y al Languedoc (fáciles para la Monarquía Hispánica desde la Cerdaña). Y sólo el 12 de noviembre de 1660, el embajador hispano en París, conde de Fuensaldaña, consiguió que la villa de Llívia quedase como un enclave hispano en el nuevo territorio galo ${ }^{10}$.

MAPA 1. Límites históricos del Rosellón y la Cerdaña.

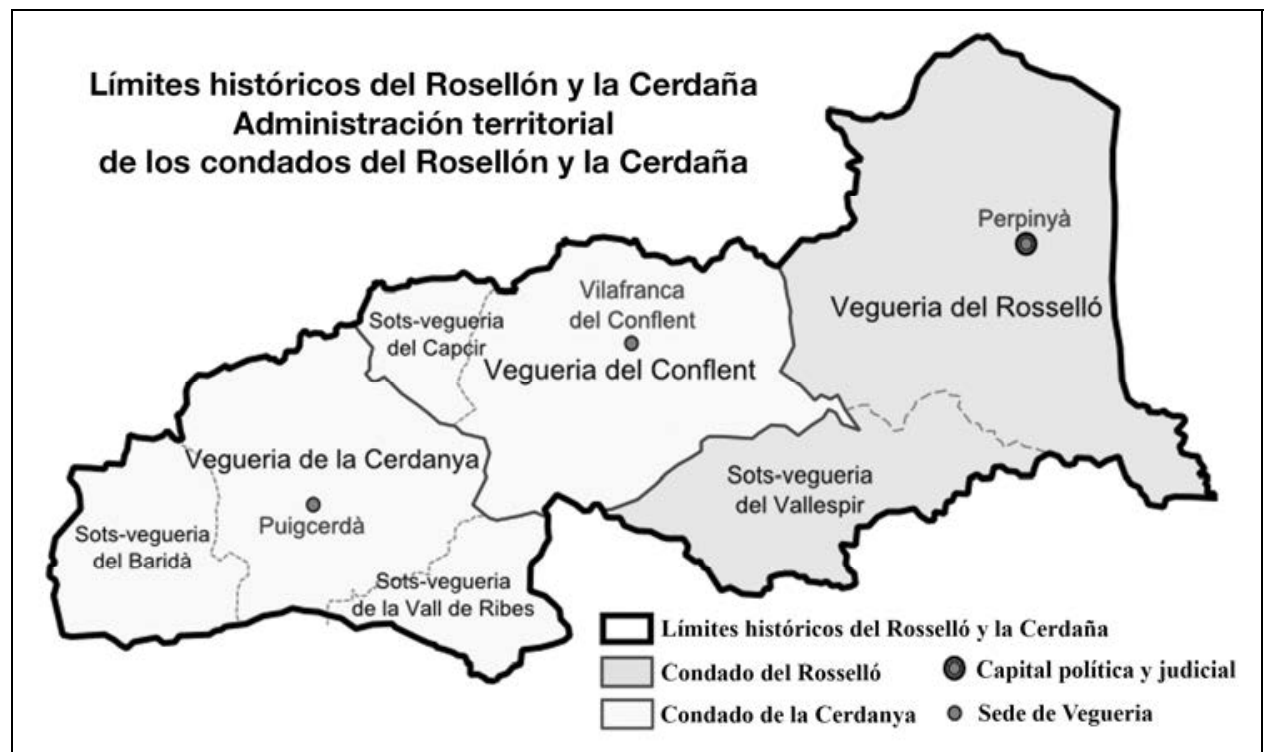

En una entrada correspondiente a 1663 , pero que prolongaba la vigencia de su información hasta 1678, el Dietari de la villa de Puigcerdà señalaba cómo Felipe IV ordenó:

10 SÁNCHEZ MARCOS, 1983: 140-159. SAHLINS, 1993: 57 ss. Según Alain Ayats, la extensión del territorio adquirido fue de 3.555 kilómetros cuadrados. AYATS, 2002: 20 y 42. 
... se redificassen las murallas desta vila las quals havian espalladas los francesos en lo any 1657 y aquellas se comensaren a redificar als 3 de Maig 1663. Y vingue lo Sr. Don Pablos de Prada [Parada] mestre de camp general per posar en execusió ditas obras alguns anys y se feu vint y dos pessas de Artillaria. Y en lo any 1678 quant lo duch de navallas [Noailles] rendi esta Vila, sen aporta la artillaria y lo dames pertret de guerra que y havia dins esta Vila que fou gran ${ }^{11}$.

No es un mal resumen de lo sucedido, pero es obvio que estamos en disposición de explicar con un cierto nivel de detalle la, en el fondo, indecisa política seguida aquellos años con respecto a cómo defender la nueva frontera catalana y, más en concreto, en la propia Cerdaña.

En un notable informe de enero de 1660, el virrey Mortara ofrecía a Felipe IV lo que bien puede considerarse el primer esbozo sobre cuál debería ser el trazado de la nueva frontera militar establecida en Cataluña tras el tratado de los Pirineos en la zona de la montaña. El problema estribaba en la indefinición del espacio a proteger. En caso de que el condado del Conflent quedase del lado hispano, en opinión de Mortara se debería fortificar allá Rodès, lugar situado sobre el coll de la Ternera, y también Vilafranca del Conflent, para poder cerrar mejor los accesos hacia el Rosellón y viceversa. Y si la Cerdaña quedaba del lado hispano, circunstancia que no dudaba, «se habrá de fortificar Puigcerdán, que es la caveça de aquel condado, y [h]oy está muy desmantelada por los franceses»;

... pero si Conflent quedase por Francia y Zerdaña por nosotros se devía añadir el fortificar en Çerdaña a un lugar que se llama Livia, que está en el camino Real que va del Conflent a Puigcerdán, junto al coll de la Percha $[\ldots]^{12}$.

Consideraba Mortara que si dichas plazas se protegían no haría falta dejar guarnición en Seo de Urgel, ni en Tremp ni en la conca de Orcau, pero, en cambio, en el castillo de València d'Àneu y en Castell-Lleó, que defendían Tremp y el valle de Arán, sí que se debería dejar alguna gente. Incluso, en caso de que la Cerdaña no fuese hispana, forzosamente se deberían fortificar Seo de Urgel y Vic. Pero de lo que Mortara estaba seguro era de que nunca podría haber mucha gente de guarnición en aquellos lugares al ser presidios de montaña, donde era difícil mantener tropas de manera permanente.

11 GALCERÁN VIGUÉ, 1977: 124. «... se reedificasen las murallas de esta villa, que habían estropeado los franceses en 1657 y se comenzaron a reedificar el 3 de mayo de 1663 . Y vino el señor don Pablo de Parada, maestre de campo general, para poner estas obras en ejecución algunos años y se hicieron veintidós piezas de artillería. Y en 1678, cuando el duque de Noailles rindió esta villa, se llevó la artillería y demás pertrechos de guerra que había en su interior que eran muchos».

12 Mortara a Felipe IV, AGS, GA, leg. 1954, 11/I/1660. 
Y en septiembre de 1660, una vez más asentada la situación, era el turno de don Baltasar de Rojas Pantoja, antiguo gobernador de las armas de Barcelona, quien había luchado en el Principado hasta 1658, de comentar las posibilidades defensivas de la nueva frontera militar de Cataluña. De Rojas creía que por la zona de la montaña era clave mantener bien fortificada y guarnecida Camprodón, pero no lo era menos tener prevenida Ripoll por aquella misma parte, y hasta Castellfollit, sobre todo en momentos de guerra abierta.

En Cerdania se debe fortificar la villa de Libia y guarnezerla porque es la avenida de Carol y de Conflent y que cubre la plaza de Cerdania, y en caso que no quedasse para V. Magd. será necesario fortificar muy de propósito Puycerdán y mejorar quanto se pueda á Bellver ${ }^{13}$.

De Rojas consideraba, en cambio, que no era necesaria la guarnición de Seo de Urgel porque las defensas de la Cerdaña la cubrían por un lado y el castillo de València d'Àneu por el otro, además del castillo de la Bastida. En el valle de Arán, Castell-Lleó debería conservar la guarnición que siempre tuvo.

Pero lejos de las estrategias generales, existían cuestiones más prosaicas como el envío de tropas efectivas, de las que se carecía en número suficiente, a las fortificaciones devueltas por Francia. Por ejemplo, en enero de 1662 apenas si había cuatrocientos dieciocho hombres en las plazas del Pirineo, desde el valle de Arán hasta Camprodón (de ellos ciento ochenta y seis en Seo de Urgel). En aquel momento todavía no se hablaba de una guarnición para Puigcerdà $^{14}$. Y los franceses actuaron en consecuencia: según A. Ayats, entre 1662 y 1664, nunca hubo más de dos mil quinientos soldados franceses en el Rosellón ${ }^{15}$. Luis XIV sabía perfectamente que la prioridad de Felipe IV por motivos dinásticos y de reputación era recuperar Portugal y la Monarquía Hispánica carecía de medios como para inquietar en la nueva frontera catalana ${ }^{16}$.

En realidad, tras la firma de la paz de los Pirineos, y como dijo don Luis de Haro, lo que más le convenía a la Monarquía era «darse gran prisa a la conquista de Portugal» ${ }^{17}$. A partir de entonces, a la hora de conceder los escasos medios de guerra con los que se contaba, se mimó al frente portugués en detrimento del catalán, el cual ya no disponía del Rosellón como salvaguarda de las acciones de Francia ${ }^{18}$.

13 Don Baltasar de Rojas a don Gregorio de Tapia, AGS, GA, leg. 1956, 5/IX/1660.

14 Mortara a Felipe IV, AGS, GA, leg. 2000, 14/I/1662.

15 AYATS, 1997: 28; 2002: 96-98.

16 ESPINO, 2014.

17 Citado en VALLADARES, 1998: 165.

18 La pérdida del Rosellón y, sobre todo, de algunas plazas de Artois llevó al marqués de Caracena a lamentar lo siguiente: "A Francia ha sido fuerza dejar muchos puestos para que nos dejen libre la conquista de Portugal». Citado en VALLADARES, 1998: 166, n. 69. 
Pero lo cierto es que los virreyes de Cataluña no cejaron en su empeño de trazar planes para la defensa de la nueva frontera militar catalana. En junio de 1662 se produjo una situación excepcional: el virrey saliente, marqués de Mortara, se constituyó en junta con el marqués de Castel Rodrigo, virrey entrante de Cataluña, para tratar sobre la forma de guarnecer la frontera del Principado. Sobre Puigcerdà se decía que debía ser fortificada con seis baluartes - una información tachada más tarde, pues en el documento se puede leer «que se fortifique fabricando valuartes» sin especificar cuantos-, y que dichas obras debían preceder a las que se realizasen en Figueras para cerrar el Ampurdán a los incursiones galas. Según sus planes, en Puigcerdà bastaría en época de paz con colocar trescientos hombres, mientras que en Bellver quedaría una guarnición de cincuenta hombres. Asimismo, el castillo de València d'Àneu dispondría de treinta hombres y Castell-Lleó de cincuenta. Pero el escollo principal era el monetario: se necesitaba un millón de reales para mantener las tropas e iniciar los trabajos en Puigcerdà (y Figueras) con continuidad, sin contar con la ayuda económica que pudieran ofrecer los catalanes, una materia cuya discusión se dejaría para otra oportunidad (pero que se tenía muy presente). El Consejo de Guerra estuvo totalmente de acuerdo con los puntos de vista expuestos ${ }^{19}$.

Pero no todas las reflexiones estratégicas acerca de la nueva frontera fueron producto de los virreyes. El obispo de Urgel escribiría angustiado por la nueva situación, tanto militar como política, de la montaña catalana en octubre de $1662^{20}$. En su cavilación señalaba que si bien el camino hacia Barcelona desde la nueva frontera quedaba jalonado por las plazas de Rosas, Gerona y Hostalric, en cambio por la montaña los franceses podían alcanzar con facilidad Puigcerdà, cuando la capacidad de reacción militar de la Monarquía Hispánica era muy limitada, pues apenas si se contaba con setenta hombres de guarnición en Bellver y otros tantos en Seo de Urgel; mientras, los franceses se encontraban con cuatro mil infantes (bien pagados) y caballería suficiente en el Rosellón. Y una vez tomadas la Cerdaña y el Urgel se podrían hacer dueños también de las tierras leridanas.

De aquí se sigue la necesidad de cerrar este paso de Cerdaña y aunque sea materia fuera de mi profesión, represento a V.S.I. no es conveniencia fortificar a Puigcerdà, sino hacerle una muy buena ciudadela, con que será muchísimo menor el gasto de hacerla y de sustentarla, fuera de que la villa, si no es los caballeros (que son muy pocos) y algunos otros son buenos vasallos de Su Magdt., el resto franceses que desean la ocasión por su mal natural viviendo aliviados y descansa-

19 Borrador de la junta tenida por Mortara y Castel Rodrigo, AGS, GA, leg. 2001, 25/VI/1662. Consulta sobre la junta de los virreyes Mortara y Castel Rodrigo, AGS, GA, leg. 2001, 25/VII/1662.

20 Sobre el obispo de Urgel y las autoridades francesas, SAHLINS, 1993: 90. 
dos y viendo a sus vecinos oprimidos y trabajados con los muchos pechos que les ha puesto Francia...

Esto aseguraba el obispo de Urgel. El Consejo de Aragón reaccionó ante aquel envite e informó a Felipe IV sobre la necesidad de levantar una ciudadela en Puigcerdà y sobre el gobierno de las plazas de la montaña ${ }^{21}$.

En 1663, pues, se tomó la decisión de reedificar las murallas de Puigcerdà, no de construir una ciudadela. En marzo de dicho año, el virrey Castel Rodrigo envió al Consejo de Estado sus primeras impresiones sobre la plaza de la Cerdaña: avanzó la posibilidad de levantar una planta con nueve o diez baluartes, pero la prudencia invitaba a que fuesen solo la mitad de dicha cifra, así como un revellín (o media luna) y un hornabeque para dominar el barranco que se hallaba a los pies de la plaza. No obstante, ya el virrey aseguraba que era crucial comenzar pronto los trabajos

... porque enllegando ottubre los fríos no permiten por los hielos el que se trabaje de cuchara, yo he adelantado la materia habiendo hecho prevenir la cantidad de cal que será necesaria y se ba haciendo en ello aún más de los possible.

También recomendaba el virrey la leva de mil alemanes — aseguraba disponer de varias ofertas de reclutamiento a buen precio llegadas desde Viena-, alegando que la gente de dicha nacionalidad «es la que mas se conserba y mejor puede resistir a los fríos de Cerdaña» ${ }^{22}$.

Y aunque en el Consejo de Estado se le prometieron 560.000 reales a Castel Rodrigo, lo cierto es que tan solo se le remitieron 160.000 y, eso sí, a falta de alemanes el tercio napolitano de don Jerónimo D. Ales, con quinientas plazas, para que comenzasen a trabajar en las fortificaciones de Puigcerdà23. Por cierto que aquel mismo verano, el ministro Louvois recibió el plano de las obras de fortificación de la plaza de la Cerdaña merced a la buena labor del intendente del Rosellón, Macqueron ${ }^{24}$.

A partir de junio de 1663, las obras en Puigcerdà comenzaron a adquirir mayores bríos. Aunque el virrey Castel Rodrigo se quejase del envío de dinero con (demasiada) falta de regularidad - en un momento dado se le habían prometido otros 180.000 reales aportados por el Consejo de Indias-, el caso es que le llegaron quinientos gastadores y maestros de obra que trabajaban incluso los días de fiesta, previa licencia, en las murallas, cuyos esfuerzos se sumarían al trabajo realizado por las tropas del tercio italiano. Aunque Castel

21 Obispo de Urgel al vicecanciller del CA, ACA, CA, leg. 411, 12/X/1662.

22 Virrey Castel Rodrigo al CE, AGS, Estado, leg. 2679, 15/III/1663.

23 Consultas del CE, AGS, Estado, leg. 2679, 27-30/III/1663. Castel Rodrigo a Felipe IV, AGS, Estado, leg. 2679, 12/V/1663.

24 La correspondencia entre Macqueron y Louvois citada en AYATS, 2002: 95. 
Rodrigo no estaba satisfecho, pues sabía que el coste de alimentar aquel millar de personas pronto acabaría con los ingresos de la pagaduría del ejército. De hecho, el virrey se conformó pronto con disponer con un total de 400.000 reales para Puigcerdà, y no los 560.000 inicialmente prometidos ${ }^{25}$.

Lo interesante del caso es la desprevención defensiva del Rosellón y el Conflent: Luis XIV apenas si decidió gastar en mejoras arquitectónicas en 1663, y aplicadas al año siguiente, 8.000 libras tournois; ello sin contar las quejas por el estado de la artillería en sus plazas. El problema era el origen hispano (y antiguo) de la mayor parte de dichas artillerías y su mal estado general (así como la falta de balería) ${ }^{26}$.

El virrey Castel Rodrigo realizó un viaje a la frontera catalana en octubre de 1663 con la intención de revisar las obras llevadas a cabo. Cabe decir que su impresión de los trabajos realizados en Puigcerdà fue más que positiva a tenor de sus palabras, dirigidas al secretario del Consejo de Guerra, Diego de Sada:

Puigcerdà es una gran plaza y se ha trabajado en su fábrica lo que no es creíble ni parece cabe en el tiempo que ha que se dio principio a ella, y estando acabado lo poco que resta para perfeccionarla no será inferior a la de Perpinyà $[\ldots]^{27}$.

Francia, a través del gran Vauban, se encargaría con los años de que ello no fuera así. Pero entre tanto, los catalanes contribuyeron con un donativo voluntario para las fortificaciones de la provincia, cuyas aportaciones se hubieron de librar desde el 15 de octubre de 1663 al 15 de abril de 1666, no sin reticencias. Según el tesorero Pere Montaner, el total a recaudar aquellos tres años era de 2.137.800 de reales, lo cual representaba 712.600 reales anuales ${ }^{28}$.

El sustituto de Castel Rodrigo al frente del virreinato catalán, don Vicente Gonzaga, no iba a ver las cosas tan positivas. Por ejemplo, en un primer informe de mayo de 1664, Gonzaga aseguraba que Puigcerdà había recibido merced al donativo voluntario de Cataluña, 185.014 reales de ardites (o de vellón, en castellano). Pero el problema detectado era que el perfeccionamiento de la plaza se llevaría otros 800.000 reales de ardites, una cantidad en la que no estaba comprendido ni el coste de la fundición de la artillería necesaria, que se haría in situ, ni el de las municiones, víveres y armas para las tropas de la guarnición. Gonzaga no pudo dejar de reconocer que las fortificaciones de Rosas y Camprodón también necesitaban de una gran suma de dine-

25 Consulta del CE, AGS, Estado, leg. 2679, 12/VI/1663. Consulta del CA, ACA, CA, leg. 318, 18/VI/1663. Consulta del CE, AGS, Estado, leg. 2680, 21/VI/1663.

26 AYATS, 2002: 101-104.

27 Virrey Castel Rodrigo a don Diego de Sada, ACA, CA, leg. 321, 20/X/1663.

28 Memorial de Pedro Montaner, ACA, CA, leg. 415, 27/I/1664. 
ro, pero que centrándose sólo en Puigcerdà, con el dinero disponible no acabaría de fortificarla aquel año ${ }^{29}$. Felipe IV, con la condición de que Gonzaga gastase en Puigcerdà la mayor parte del dinero producido por el donativo catalán, le prometió un cuarto de millón de reales de plata para acabar aquellas obras. Y ya era esta una cantidad reducida, pues el Consejo de Estado había hecho suya la cifra anteriormente propuesta por el virrey Castel Rodrigo (400.000 reales para Puigcerdà y otros tantos para las restantes plazas catalanas) ${ }^{30}$. Justo en aquel momento se entraba en una lamentable espiral de demandas a la baja, con Felipe IV — y su Real Hacienda — , como personaje silente. En julio, Gonzaga clamaba no ya por 250.000 reales, sino por 120.000 , pero, eso sí, para estimular de alguna forma la respuesta del monarca, informó que el gobernador del Roselón había realizado un reconocimiento de la frontera y para realizar el opósito de la plaza de Puigcerdà había elegido el castillo de Bolquera, situado en el coll de la Perxa, que los franceses intentarían reforzar ${ }^{31}$.

En primavera de 1665, el virrey Gonzaga aseguraba que el gasto realizado en las defensas de Puigcerdà había alcanzado los 852.941 reales de plata (o 1.450 .000 reales de ardites), pero necesitaba los 250.000 reales de plata prometidos, además de una leva de 500 o 600 castellanos (que pronto rebajaría a 400) para la guarnición de Puigcerdà, que se estipulaba en mil doscientos hombres, ampliables a dos mil quinientos en caso de guerra. La falta de respuesta llevó a un cada vez más afligido Gonzaga a recordar, además, la necesidad de componer también Camprodón, Berga, Castellfollit, el castillo de València y Castell-Lleó, y asegurar, además, Seo de Urgel y Figueras, sin olvidarse de Cadaqués, Rosas y Palamós, así como Lérida y Barcelona, sin mencionar ya las plazas de la retaguardia ${ }^{32}$. Los ya famosos 250.000 reales no se recibieron. En septiembre de 1665, Gonzaga escribía a don Diego de la Torre, secretario del Consejo de Guerra, que se conformaba con los 52.000 reales que le habían prometido últimamente a través del asentista don Sebastián de Oleaga, y «si vinieren» los emplearía únicamente en las fortificaciones de Puigcerdà 33 .

29 Gonzaga a Felipe IV, AGS, GA, leg. 2053, 23/II/1664; consulta del CG, AGS, GA, leg. 2053, 5/III/1664. Consulta del CA, ACA, CA, leg. 318, 4/IV/1664. Relación de Juan de Gachapay, pagador del ejército de Cataluña, CA, ACA, CA, leg. 318, 27/V/1664.

30 Gonzaga a Felipe IV, ACA, CA, leg. 318, 31/V/1664. Gonzaga a Felipe IV, AGS, GA, leg. 2054, 7/VI/1664. Consulta del CG, AGS, GA, leg. 2054, 18/VI/1664. Don Pere Montaner a don Vicente Gonzaga, AGS, GA, leg. 2054, 23/V/1664. Don Pedro Montaner al vicecanciller del CA, ACA, CA, leg. 416, 31/V/1664.

31 Consultas del CE, AGS, Estado, leg. 2681, 25/VI/1664 y 31/VII/1664.

32 Gonzaga a Felipe IV, AGS, GA, leg. 2083, 28/III/1665. Consulta del CG, AGS, GA, leg. 2083, 17/IV/1665.

33 Consulta del CG, AGS, GA, leg. 2083, 20/V/1665. Gonzaga a don Diego de la Torre, AGS, GA, leg. 2083, 12/IX/1665. Gonzaga a Felipe IV, ACA, CA, leg. 418, 20/VI/1665. 
En noviembre de 1665, apenas dos meses después de la muerte de Felipe IV, el virrey Gonzaga escribía a Mariana de Austria acerca de las guarniciones catalanas de la montaña. Puigcerdà, apenas si tenía doscientos doce efectivos guardando sus muros, pero otros casos eran realmente escandalosos: en Camprodón quedaban ocho hombres, en Castellfollit doce, en Berga dos, en Seo de Urgel ninguno. El Consejo de Guerra puso el grito en el cielo y aseguró tener informes que señalaban cinco mil efectivos franceses en el Rosellón. Lo cual no era cierto: datos aportados por Alain Ayats señalan poco más de mil seiscientos efectivos franceses en los condados; pero Gonzaga apenas si contaba con mil cuatrocientos efectivos en todo el Principado ${ }^{34}$. No es de extrañar, pues, el bajo número de tropas de guarnición en los condados del Rosellón y del Conflent. Luis XIV sabía perfectamente que nada había de temer, sobre todo mientras la guerra de Portugal siguiese en marcha. Y lo estaría hasta 1668.

Ahora bien, la muerte de Felipe IV sin duda iba a traer consecuencia diplomáticas importantes, que se empezaron a dejar sentir pronto en los Países Bajos. Mientras, en la frontera catalana los nuevos informes enviados no hicieron sino confirmar el mal estado defensivo general. En una consulta del Consejo de Guerra de enero de 1666 se avisaba de una situación lamentable: la falta galopante de armas y tropas que había en los presidios de Cataluña a partir de un informe sobre las plazas fortificadas. En cuanto a Puigcerdà, se insistía en su falta de tropas de guarnición,

... que [h]oy no la[s] tiene ni aún para suplir las centinelas nezesarias; si debe hazer deffensa real fáltale acavar de cubrir el foso y dos baluartes, a la parte que mira a Bellver fáltale la estrada encubierta, hazer las dos tenazas, las estacadas y el terreno que aún se le debe entrar.

Sobre municiones y demás las necesidades eran de mil quintales de pólvora, mil de plomo y mil quinientos de cuerda, pero, además, no tenía prevenciones la plaza de tablones, cestos, cajas y maderas para la artillería, ni para preparar fuegos de artificio; también faltaban mil armas de fuego, seiscientas picas, trescientos chuzos, el mismo número de partesanas y al menos cien petos y morriones. Tampoco había ninguna reserva de víveres prevenida, ni capotes, mantas y jergones para el personal, especialmente cuando estaban de centinela. Asimismo,

Consulta del CA, ACA, CA, leg. 319, 10/VII/1665. Consultas del CE, AGS, Estado, leg. 2683, 9-14/VII/1665 y 5/IX/1665.

34 Don Vicente Gonzaga a Mariana de Austria, ACA, CA, leg. 1337, 23/XI/1665. Consulta del CG, AGS, GA, leg. 2086, 7/X/1665. AYATS, 2002, 133-144. 
... se debe considerar que esta plaza [h]oy tiene el país del enemigo a tiro de mosquete y una vez que se doble allá no será fazil platicar el socorro ni introduzir lo que faltare.

La plaza de Camprodón se encontraba sin estacada, sin rastrillos y con unas puertas necesitadas de reparos, así como sus cisternas y sus murallas; tampoco había cuarteles en su interior y, por consiguiente, no se contaba con materiales para hacer la vida soportable a las tropas; poca artillería y desmontada, sin apenas armas, ni víveres ni otros pertrechos necesarios para soportar un sitio. La idea era perfeccionarla aquella misma primavera al nivel de poder soportar un sitio con artillería, pues si caía, al ser aquel puesto la «llave de la montaña», «el enemigo queda dueño de ella [la montaña] [y] deja cortado a Puigcerdán y abierta la puerta para traer con fazilidad la artillería a ganar aquella plaza $[\ldots] \gg^{35}$. El virrey Gonzaga, si esperaba encontrar en Mariana de Austria y sus consejeros de gobierno unos interlocutores más atentos a sus demandas, se equivocó. Aunque argumentase que Cataluña podía caer en apenas ocho días en manos de Francia ${ }^{36}$.

Salvo una cantidad irrisoria llegada en enero de 1666, 65.761 reales, que Gonzaga destinó a las fortificaciones catalanas, solo en mayo de dicho año llegaron por fin 320.000 reales que empleó en mejorar las defensas de plazas como Puigcerdà, Castellfollit y Camprodón, además de Rosas. En el caso de Puigcerdà,

... es increyble el gasto y el trabajo, y aun nezesita de tiempo para acavarle como de ordinario suzede en las fortificaciones grandes, pero si tuviese víveres, muniziones y gente dirá su razón el estado en que $[\mathrm{h}]$ oy se halla $[\ldots]^{37}$

Pero para que se puedan comparar los gastos realizados con los necesarios, en este informe se mencionaba cómo solo Palamós necesitaba 330.000 reales, y Tarragona otros 130.000 reales. Pero aquel impulso monetario se difuminó en poco tiempo. En febrero de 1667, Jerónimo D. Alés, quien seguía al frente de sus escasos hombres como gobernador en Puigcerdà, escribía a don Cristóbal Crespí de Valldaura, vicecanciller del Consejo de Aragón, para explicarle que en los cuatro años que la gobernaba con su tercio nunca había tenido medios adecuados para acabar la fortificación ni tropas suficientes para su guarnición, y sus hombres se hallaban, además, desnudos, enfermos, hambrientos y desmoralizados; Alés había contraído algunos empeños para poder

35 Gonzaga a Mariana de Austria, ACA, CA, leg. 418, 16/I/1666.

36 Las citas en Consulta del CG, AGS, GA, leg. 2110, 7/I/1666. Consultas del CA, ACA, CA, leg. 320, 14-26/I/1666. Consulta del CE, AGS, Estado, leg. 2684, 22/I/1666.

37 Gonzaga a Mariana de Austria, ACA, CA, leg. 418, 23/I/1666. Gonzaga a Mariana de Austria, AGS, Estado, leg. 2684, 26/V/1666. 
darles algo de comer a su gente. Una situación insostenible. La respuesta del Consejo de Aragón fue contundente: había que hacer caso de lo que decía el maestre de campo Alés, ya que si Puigcerdà caía y los franceses metían allá tres mil infantes y mil efectivos de caballería, no sólo no serían expulsados, sino que pondrían en peligro las restantes plazas de la zona que dependían de ella en cuanto a su seguridad, como Lérida, Vic o Seo de Urgel. De ahí que fuese tan urgente el envío de medios de guerra, tropas y dinero, para guarnecer mejor la frontera catalana ${ }^{38}$.

A fines de marzo de 1667, el virrey Gonzaga reconocía que apenas si había mejorado algo la situación de las guarniciones del Pirineo, pues en Puigcerdà había doscientos diez hombres de guarnición, setenta en Camprodón y veinticinco en Castellfollit. Temía que si Francia atacaba, aunque fuese con cuatro mil infantes y mil quinientos caballos, podían permitirse dejar de lado tanto Puigcerdà como Camprodón y lanzarse a ocupar la montaña tomando Cardona, Vic, Berga y Ripoll, con lo que controlarían el centro de Cataluña. Y ponía como ejemplo sobre tan dantesca situación el estado de cosas en Puigcerdà, una plaza que necesitaría para su resguardo de nada menos que tres mil hombres, o la propia Barcelona, donde apenas había seiscientos hombres de guarnición en aquel momento. Pero había más. Como en otros lugares, las autoridades hispanas no podían fiarse de las intenciones de los habitantes de Puigcerdà, una villa con «un pueblo numeroso y poco afecto» ${ }^{39}$.

\section{LA GUERRA DE DEVOLUCIÓN, 1667-1668}

E1 24 de mayo de 1667 un Real Decreto informaba de la ruptura de la paz por parte de Francia. Iba a ser el primer conflicto del reinado de Carlos II $^{40}$. Ciertamente, la guerra se centró en los Países Bajos hispanos, donde en 1667 los franceses tomaron doce plazas - Lille se rindió a los dos días de iniciarse el sitio-, y en quince días ocuparon el Franco Condado en 1668. Pero no estaban preparados para un conflicto en el Rosellón. Como reconoció el intendente Macqueron a Louvois en agosto de 1667,

38 Jerónimo D. Alés a Crespí de Valldaura, ACA, CA, leg. 421, 28/II/1667. Consulta del $C A$, ACA, CA, leg. 321, 17/III/1667.

39 Gonzaga a Mariana de Austria, AGS, GA, leg. 2133, 26/III/1667. Gonzaga a Mariana de Austria, AGS, Estado, leg. 2686, 2-23/IV/1667.

40 Sobre la estrategia hispana aquellos años, sobre todo en cuanto al frente flamenco del conflicto, sobre el que pivotaron los demás frentes, HERRERO SÁNCHEZ, 2000: 166-176. Sobre la estrategia francesa en este conflicto, CÉNAT, 2010: 91-93. 
... toutes nos places ont un besoin extreme de munitions de bouche, et si on en les pouvoit pourvoir presentement de touttes choses, on pouroit au moins y envoyer quelques bleds en attendant, n'y en ayant pas un grain dans aucune ${ }^{41}$.

El trigo que pudieron confiscar les fue entregado a las tropas destacadas en la Cerdaña gala y el Conflent, y el propio duque de Noailles hubo de desembolsar de su peculio 9.950 libras para mantenerlas. Ante la falta de tropas, se obligó a los roselloneses a prestar servicio de milicia y solo llegaron nuevas tropas en octubre. Por otro lado, el estado de la artillería en las plazas de los condados seguía siendo mediocre, pues en Perpinyà, que contaba con setenta y tres piezas, solo una era del calibre de veinticuatro libras de bala y las restantes de un calibre igual o inferior a doce libras de bala ${ }^{42}$. Por lo tanto, no es de extrañar que el nuevo virrey de Cataluña, duque de Osuna, pudiera sorprender al enemigo en aquel conflicto.

En junio de 1667, el obispo de Urgel informaba al Consejo de Aragón sobre cómo el gobernador de Puigcerdà, Jerónimo Alés, se había encerrado en la plaza con cuatrocientos soldados y la milicia de la villa, un total de dos mil hombres, para defender la posición. Parecían contar con bastante trigo. Pero el duque de Osuna, siempre cauteloso, no se fiaba de los trescientos efectivos de caballería de los que disponía Francia en el Rosellón ${ }^{43}$. No iba desencaminado el virrey, pues las tropas del duque de Noailles se atrevieron aquellas jornadas a adelantar posiciones y sitiar Llívia, en realidad apenas una iglesia y una torre defendidas por un capitán y treinta infantes. Cuando le llegó el aviso del ataque, Osuna hizo enviar caballería desde Barcelona así como cinco compañías de Rosas y Palamós, pero era difícil movilizar más tropas porque apenas disponía de ciento treinta caballos fuera de los que había de guarnición en algunas plazas; con todo, el virrey escribió a Seo de Urgel y contornos para que comenzaran a movilizar, y enviar a la Cerdaña, todos los recursos militares que pudieran. El peligro, tal y como lo percibía Osuna, era un sitio formal de Puigcerdà, porque la capital de la Cerdaña cubría el país hasta Barcelona, ya que Gerona quedaba a un lado y no estorbaría en sus evoluciones al contrario; además, no era plaza que pudiese aguantar ni cuatro días si no disponía de un ejército poderoso como guarnición; además, el enemigo podía tomar pie en la Cerdaña y saquearla o quedarse alojado, atacando además la comarca vecina de Urge ${ }^{44}$.

Un Osuna un tanto melancólico informaba al Consejo de Estado que el

41 La correspondencia entre Macqueron y Louvois citada en AYATS, 2002: 145-160.

42 La correspondencia entre Macqueron y Louvois citada en AYATS, 2002: 145-160.

43 Obispo de Urgel a don Diego de Sada, secretario del CA, ACA, CA, leg. 421, 9/VI/1667. Osuna a Mariana de Austria, ACA, CA, leg. 321, 8/VIII/1667.

${ }^{44}$ Consulta del CA, ACA, CA, leg. 321, 10/IX/1667. Osuna a Mariana de Austria, AGS, GA, leg. 2160, 24/IX/1667. 
... descaecimiento de los ánimos de estos naturales para defenderse por sí solos es grande y claramente muestran que ni pueden ni lo han de hacer. Bien juzgo que si ven tropas que los mantengan, muchos serán firmes en el servicio de V. M., pero si no, muy pocos.

El miedo a que Francia encontrase adeptos en Cataluña, como hacía apenas unos años atrás era grande, pero también hubieron de llegar rumores al virrey sobre los problemas habidos en el Rosellón a causa de la gabela de la sal, pues afirmó: «puedo asegurar a V. Magd. cada día más que no son los peores vasallos que tiene V. Magd. los de Rosellón, y que si hubiera fuerzas se viera mejor y muy presto». El Consejo de Estado, receloso, contestó refiriendo la calamidad que significaría perder entonces Puigcerdà, con lo mucho que había costado, y estaba constando, edificar, poniendo en peligro toda la frontera. Se solicitó una vez más dinero y tropas de forma urgente, pues los franceses estaban adelantando posiciones sin apenas efectivos, una situación lamentable ${ }^{45}$.

El caso es que el duque de Osuna se sacudió el letargo y decidió pasar a la acción. Tras el ataque francés a Llívia, el virrey pudo enviar a la Cerdaña hasta dos mil trescientos infantes, entre tropas regulares y gente del país, y doscientos caballos, que consiguieron la retirada de las tropas francesas hacia el Conflent. En carta a don Diego de Sada, Osuna aseguraba que las pérdidas francesas se cifraban en ciento cincuenta y cinco bajas entre muertos, heridos y prisioneros. Los soldados de Osuna consiguieron un buen botín a costa de los franceses, habiendo perdido por su parte apenas seis hombres, diez heridos y doce prisioneros, con cuatro caballos muertos. Sólo un oficial resultó herido. En esta ocasión se había conseguido que cincuenta y cinco lugares del valle de Querol y de la Cerdaña francesa diesen la obediencia a Carlos II. En vista de ello, Osuna envió de refuerzo cien efectivos de caballería y cuatrocientos infantes, todos ellos procedentes de tercios catalanes, con la esperanza de que los naturales retirasen su cosecha con tranquilidad, pero sobre todo para que una vez llegado el invierno, hacia noviembre en aquel país, sus tropas pudiesen presionar para que los lugares del Capsir también diesen la obediencia a España. El virrey quería, incluso, esperar un poco más con toda aquella gente desplegada, asegurando que las nieves impedirían el envío de ayuda militar francesa a la zona ${ }^{46}$.

La documentación francesa exhumada por Alain Ayats explica una historia ligeramente distinta. Según Ayats, a fines de septiembre los franceses se reti-

45 Osuna a Mariana de Austria, AGS, Estado, leg. 2686, 10/IX/1667. Consulta del CE, AGS, Estado, leg. 2686, 19/IX/1667.

46 Virrey Osuna a don Diego de Sada, ACA, CA, leg. 420, 8-29/X/1667 y 7/XI/1667. Osuna a Mariana de Austria, ACA, CA, leg. 420, 15/X/1667. Consulta del CA, ACA, CA, leg. 321, 27/X/1667. Consultas del CG, AGS, GA, leg. 2135, 21-26/X/1667. 
raron del llano de la Cerdaña, momento aprovechado por el gobernador de Puigcerdà para invadir la Cerdaña gala, alcanzando Bolquera y Formiguera con mil quinientos infantes y trescientos caballos. Noailles partió de Perpiñán ante aquella noticia con algunas tropas y cuando alcanzó Vinçà, el gobernador Alés ya retrocedía hacia la Cerdaña, luchando ambos ejércitos ante Puigcerdà, donde los españoles tuvieron un centenar de heridos y muertos $\mathrm{y}$ once prisioneros, por siete $\mathrm{u}$ ocho bajas del lado galo ${ }^{47}$.

En cualquier caso, la iniciativa estaba claramente del lado hispano y en enero de 1668 trescientos efectivos de la guarnición de Puigcerdà al mando del sargento mayor de la plaza atacaron y pillaron tres casas en Fontpedrosa, siendo rechazados por las milicias catalanas de la zona, como no podía ser menos. Ayats lo entiende bien: "Il s'agit néanmoins bien plus d'un réflexe d'autodéfense que d'una collaboration gratuite avec les Français". En marzo, de nuevo se movilizó parte de la guarnición de Puigcerdà y setecientos hombres del somatén para hacerse una vez más con Formiguera e, incluso, con Sautó, de modo que el teniente general Foucault, quien escribía alarmado al ministro Louvois, ya veía a las tropas hispanas ante Prada del Conflent si no fuera por la mucha nieve caída que se lo impediría. Foucault reclamaba más medios de guerra ${ }^{48}$.

Desde el lado hispano de la frontera, ahora en entredicho, las cosas se veían de manera distinta. Joan de Mir, veguer de la Cerdaña, escribía al Consejo de Guerra en enero de 1668 lamentando las noticias recabadas aquellos días, en el sentido de que Luis XIV deseaba aumentar la recluta de tropas catalanas en el Rosellón merced a la labor de catalanes huidos desde hacia años, como don Josep de Margarit, aunque también se hablaba del envío del duque de Orléans con dos mil hombres de refuerzo, cuando ellos se encontraban en tan mala situación. Y añadía:

... están tan flacas nuestras fuerzas que quatro picaros de migaletes de Fransia no podemos sacar de las casas de la Perxa [...] y en siendo fuera la nieve del llano no podremos salir los pies de la plasa [de Puigcerdà].

Aseguraba que una vez terminada la fortificación, Puigcerdà necesitaría igualmente dos mil infantes y trescientos caballos de guarnición, y como sólo había unas trescientas casas en la villa, no se podrían alojar en ella tantos hombres. La única solución sería construir cuarteles. Mir estaba convencido, de no tomarse dicha medida, cómo muchos habitantes de Puigcerdà acabarían por abandonar su tierra, cuando eran tan leales vasallos. Es más, propuso que Carlos II enviase trescientos o cuatrocientos caballos para repartirlos entre los na-

\footnotetext{
47 AYATS, 2002: 154-156.

48 AYATS, 2002: 162-165.
} 
turales, quienes harían una muy buena tropa de caballería, belicosa y de calidad, y si les diesen, caballo, pan y cebada, además de exención de alojamientos, muchos se apuntarían a la idea de servir al rey, ya que podrían cuidar de sus tierras al mismo tiempo. Lógicamente, los oficiales deberían asimilarse a los del ejército real y cobrar sus sueldos. Mir propuso como posibles cuarteles los dos conventos de religiosos de la villa y el de monjas como hospital militar ${ }^{49}$.

En realidad, según el Dietari de la fidelíssima vila de Puigcerdà, el 26 de agosto de 1667 se deliberó en el consejo de la villa levantar un cuartel para el alojamiento de la caballería que estuviese de guarnición en la Cerdaña; una manera de evitar su alojamiento en casa de particulares. El cuartel se empezó a edificar en la enfermería del convento de San Agustín aprovechando terrenos de un huerto, a pesar de las objeciones del gobernador Alés, para quien el mejor lugar para levantar un cuartel en Puigcerdà era la enfermería del convento de San Francisco (en su prolongación hasta la casa del señor Guillem Compte). El cuartel lo construyó el maestro de casas Antoni Labro, y para el 24 de marzo de 1668 las obras estuvieron finiquitadas con un coste de 440 ducados de plata. También tenemos constancia de un segundo cuartel para ¿cien soldados? de infantería que se inició el 20 de abril de 1668 y se terminó de edificar el 18 de marzo de 1669 con un coste de 1.298 libras catalanas ${ }^{50}$.

Esos gastos nos llevan a entender la actitud de Puigcerdà, que en julio de 1667 solicitaban a Mariana de Austria que se les eximiese del pago del maridaje de la emperatriz de Alemania, esposa de Leopoldo I, que montaba 236 libras y 14 sueldos, a causa de los muchos gastos de sostenimiento de la guarnición que tenían. El Consejo de Aragón buscó la aprobación de la medida y señalaba cómo

... siendo [h]oy aquella villa el presidio de frontera de Francia más próximo y expuesto a invasión deviendo acudir con fineza y puntualidad a su defensa, es justo favorecerles $[\ldots]$.

Y la reina gobernadora estuvo de acuerdo ${ }^{51}$.

Por su parte, también en enero de 1668, don Gabriel de Llupià, gobernador de Cataluña, se vio en la obligación de escribir al vicecanciller del Consejo de Aragón para advertirle sobre la situación defensiva de Puigcerdà, donde había que finiquitar la estrada cubierta, construir la media luna de la puerta principal y acabar una tenaza muy importante para impedir que Francia viese la empresa factible y se lanzase a por ella,

49 Juan de Mir, veguer de la Cerdaña, al CG, AGS, GA, leg. 2191, 7/I/1668.

50 GALCERÁN VIGUÉ, 1977: 123-124. Ajuntament de Puigcerdà, registre de Consells, ACCE, 7/XI/1662 a 11/X/1667.

51 Consulta del CA, ACA, CA, leg. 210/16 y 6/VII/1667. 
... y Dios no permita que la perdiésemos, que jamás la volveríamos a recobrar, porque nosotros no podríamos subir allí artillería y el enemigo sí, y sería señor de toda la montaña.

El Consejo de Aragón estuvo con él en dicha apreciación, y añadió que en otras plazas como Rosas, Castellfollit, Hostalric y Camprodón había mucho por hacer y faltaban fondos en todas partes, porque sólo se contaba con la prórroga del donativo que Cataluña había concedido para sus fortificaciones en 1663, y el primer pago se haría en abril de aquel año. Estando así las cosas, se entendía que los franceses pudieran progresar con tranquilidad en su política agresiva en la frontera, sin miedo a un traspiés, mientras en Cataluña crecía la inquietud por la falta de medios de guerra de la Monarquía ${ }^{52}$. ¿Pero esa percepción era cierta? El caso es que siguiendo los trabajos de Alain Ayats, no. Las autoridades francesas del Rosellón estaban muy preocupadas por el resultado del conflicto en 1667 en la frontera catalana. Y la mejor prueba es que cuando se firmó la paz de Aquisgrán en mayo de 1668 se trazaron unos primeros planes para mejorar las defensas del Rosellón.

Todavía en primavera de 1668 el virrey Osuna realizó un viaje a la nueva frontera catalana

... compadeciéndome del mal estado en que he hallado las plazas de la frontera y con razón pide la de Girona y Puigcerdán lo necesario porque les falta mucho aunque se prevenga por mi parte con quanto cave en lo posible [...]

admitía Osuna al secretario don Diego de Sada lo muy

... desconsolado que me tiene la floxedad con que hay se resuelve qualquiera materia que toque a esta defensa, pues aún después de haverse ajustado la paz de Portugal veo que no nos adelantamos en nada sino que se va con mayor lentitud en todo [...]

De hecho, desconsolados estaban los cónsules de Puigcerdà, quienes en carta a Mariana de Austria reclamaron todos los medios de guerra necesarios para evitar caer en manos de Francia, con la argumentación de que si eran conquistados, no habiendo otras defensas, se entiende, podía caer media Cataluña. El problema, como siempre era el dinero: apenas si se podía confiar en lo recaudado en el propio Principado por la vía de la prórroga del donativo voluntario, unas escuálidas 20.100 libras que Osuna había destinado a las fortificaciones de Palamós, Puigcerdà, Rosas, Tarragona y San Juan de los Alfa-

52 Don Gabriel de Llupià al vicecanciller del CA, ACA, CA, leg. 423, 7/I/1668. Consulta del CA, ACA, CA, leg. 232, 8/II/1668. 
ques. Y, también, la falta de tropas: en junio Osuna envió ciento veinte efectivos de caballería de vigilancia a la Cerdaña ${ }^{53}$.

Pero esa aflicción de los cónsules de Puigcerdà quizá encubría una esperanza: Osuna escribió al Consejo de Estado para comentar cómo los cónsules le habían comunicado su interés de que los treinta y tres lugares de la Cerdaña francesa - situados hasta el puente del río Tet-, que el año anterior volvieron a la obediencia de España no se retornasen otra vez al dominio de Luis XIV, causándoles graves perjuicios el no hacerse así, por ser muy ricos y los habitantes de Puigcerdà tener en ellos haciendas de las que obtenían buenos frutos; el señuelo era considerar, pues, el empobrecimiento de la gente de Puigcerdà y ello se reflejaría en la reducción de sus posibilidades de servir a Carlos II. El Consejo de Estado dictaminó de manera un tanto cáustica que los lugares eran, en realidad, de poca consideración y por las paces de 1659 pertenecían a Francia, y por ello se retornarían otra vez, ya que no merecía la pena romper las negociaciones de paz por tan poca cosa. En realidad, el 9 de junio Osuna informaba que el gobernador de Perpiñán le había escrito para notificarle la publicación de la paz en París, una novedad que reafirmó al Consejo de Estado en su voluntad de no crear complicaciones de última hora en la frontera catalana ${ }^{54}$.

Tampoco olvidemos que por la paz de Aquisgrán Francia retornaba el Franco Condado. La entrega de los lugares de la Cerdaña francesa ocupados se realizó en diciembre de 1668, momento aprovechado por el duque de Osuna para explicarle al Consejo de Estado cómo los franceses llevaban nueva artillería a Perpiñán, fortificaban Vilafranca de Conflent, hacían levas en el Languedoc, y se rumoreaba que el barón de Montclar iba destinado al Rosellón con seis mil hombres, cuando él carecía de dinero para mantener su, por otra parte, escuálido ejército ${ }^{55}$.

Entre tanto, los franceses tomaron buena nota del tímido, pero no por ello menos real, avance hispano en la Cerdaña adquirida en 1659 y dispusieron los primeros planes para mejorar las fortificaciones de los condados del Rosellón y Conflent. En abril de 1668 llegó al Rosellón procedente del frente de Flandes el caballero de Clerville; muy pronto informó sobre la necesidad de mejorar las defensas de Vilafranca del Conflent para oponerse a cualquier avance hispano desde Puigcerdà. Pero, poco después, sería el ingeniero Chamois el

53 Osuna a don Diego de Sada, ACA, CA, leg. 424, 7/IV/1668. Osuna a Mariana de Austria, AGS, GA, leg. 2164, 23/VI/1668. Esta última misiva incluye la de los cónsules de Puigcerdà a la reina gobernadora.

54 Consultas del CE, AGS, Estado, leg. 2687, 29/V/1668, 19/VI/1668 y 31/VII/1668.

55 Consulta del CE, AGS, Estado, leg. 2687, 23/XII/1668. Ayats confirma la llegada de artillería y decenas de miles de balas procedentes del Franco Condado. AYATS, 2002: 203-204. 


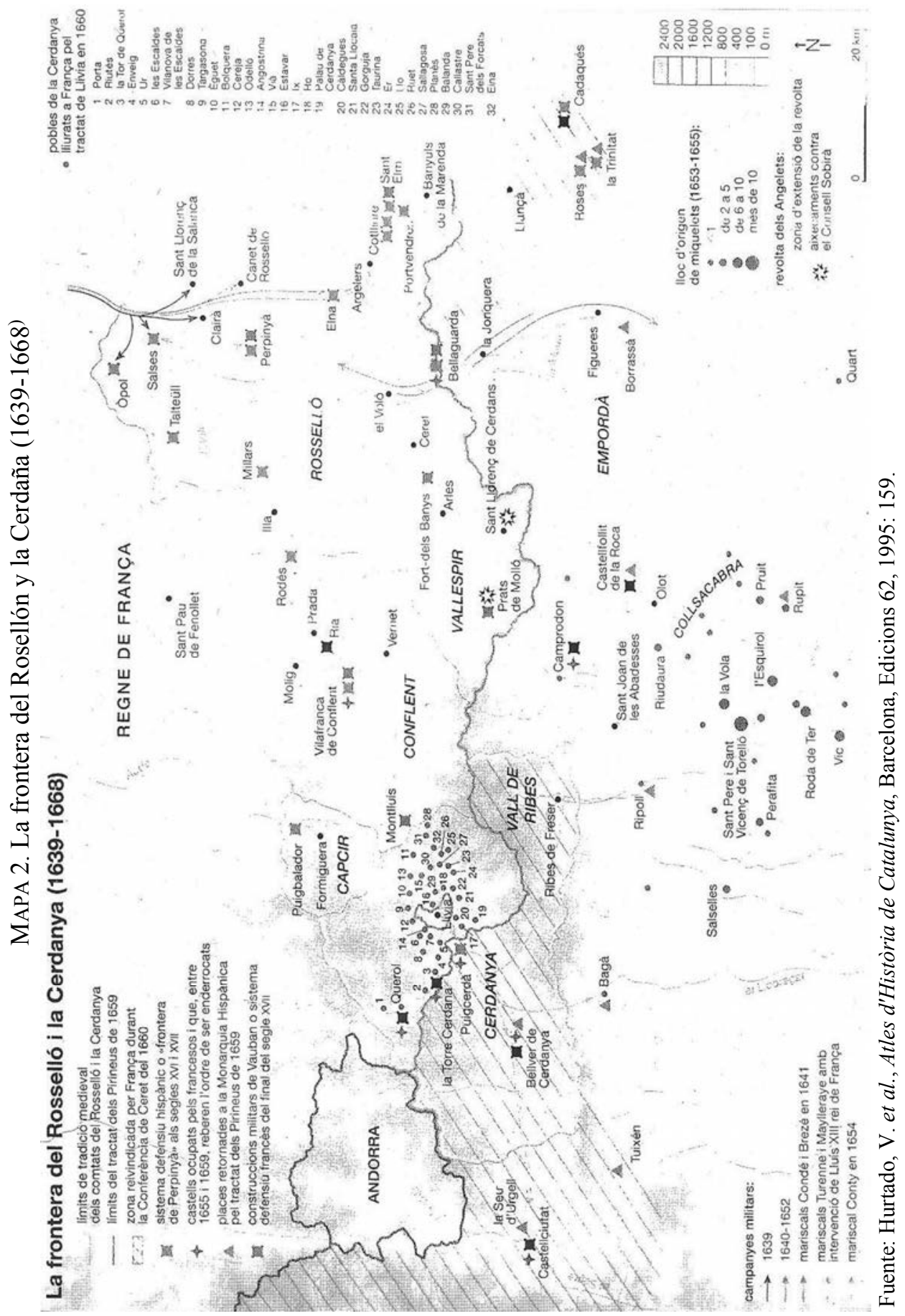

Hispania, 2017, vol. LXXVII, nº. 257, sept.-diciembre, págs. 705-733, ISSN: 0018-2141, e-ISSN: 1988-8368, doi: 10.3989/hispania.2017.019 
primero en sugerir la construcción de una fortificación de seis baluartes en Bolquera para servir de opósito a Puigcerdà. También se trató la posibilidad de construir un fuerte que dominase la plaza de Vilafranca del Conflent, con un coste de 25.000 o 30.000 escudos franceses. El intendente Macqueron, por ejemplo, era más bien de la opinión de mejorar las defensas de Vilafranca y emplear una suma como aquella en enmendar las fortificaciones de la propia Perpiñán. En todo caso, el ministro Louvois transmitió la idea de Luis XIV de limitarse a una guerra defensiva en el Rosellón, y con una Vilafranca bien fortificada, que impidiese una fácil caída en manos hispanas en caso de ser sitiada, se conformaba por el momento. Y poco más.

Como señala Alain Ayats, los españoles también sabían que una acción suya contundente en el Rosellón se traducirá inmediatamente en represalias en las fronteras de Flandes. Pero la guerra de Holanda (1672-1678) cambiaría todas aquellas percepciones. Con todo, un nuevo ingeniero, Saint-Hillaire, trazaría algunos planes defensivos para Vilafranca a fines de 1668 por valor de 50.000 libras. No obstante, consciente de la necesidad de ahorrar dinero, Saint-Hillaire trazó un plan alternativo por valor de 9.000 o 10.000 libras con el que se podrían obtener algunos resultados aceptables; además, algunos impuestos sobre el vino o el hierro en el Conflent podrían producir de 5.000 a 6.000 libras anuales, y así, los arreglos de la plaza podrían prácticamente autofinanciarse.

Por último, en la visita realizada al Rosellón por el gran Vauban en 1669, quien pensó al conocer el entorno de Vilafranca que esta era bien capaz de resistir un sitio de diez mil o doce mil hombres si se encerraban en la plaza de cuatro mil a cinco mil efectivos - la mayor parte de ellos milicias del Conflent, además de algunas tropas - , pues la esterilidad de la tierra no permitiría prolongar un sitio más allá de tres semanas o un mes. Y ello sin hablar de la dificultad para transportar artillería de batir. De acuerdo con los planes de Saint-Hillaire, Vauban también propuso construir defensas ante las dos puertas de Vilafranca (dos medias lunas), así como un foso de quince pies de profundidad rodeando la villa; y lo más importante, creyó como su predecesor Chamois en la necesidad de construir un fuerte para controlar la única posición elevada a partir de la cual se impediría toda posibilidad al enemigo de abrir ramales de trinchera para sitiar Vilafranca. Con todas aquellas construcciones, Vauban creía que la plaza estaba segura con una guarnición de trescientos hombres y la ayuda de sus habitantes. Pero Luis XIV no cambió sustancialmente de opinión ${ }^{56}$. No parece que aquellos planes fueran conocidos por las autoridades hispanas.

56 AYATS, 2002: 166-188, 222-224, 236-238, 246-247. 


\section{DE CAMINO A LA GUERRA DE HOLANDA, 1669-1672}

En enero de 1669 se envió desde Puigcerdà un confidente al Rosellón y regresó con el rumor de la llegada inminente de ocho mil infantes y dos mil caballos e, incluso, que Luis XIV iba a personarse en Perpiñán. Justamente este tipo de noticias, alarmantes, pero sin contrastar, acababan con la paciencia del duque de Osuna, quien escribió al Consejo de Guerra el 27 de julio de 1669 en el sentido de que

... los intentos que franzeses pueden tener a la plaça de Puycerdàn $[. .$.$] responde$ que tubo estas noticias por de poquísima sustancia y más quando todos los avissos que se han dado por aquella plaça han padeçido falta de verdad, pero que en medio de eso estará con cuydado a todas [h]oras por la conservación desta i las demás plaças $^{57}$.

Pero el exabrupto del virrey bien podía ocultar su preocupación, y hastío, por las muchas quejas llegadas desde la Cerdaña a partir de abril de 1669. El Consejo de Guerra trató el 8 de dicho mes un aviso de Mariana de Austria respecto a la desprevenida situación de la plaza ceretana «y lo mucho que padeçe la gente de aquel presidio con lo demás que refiere de su desnudez y enfermedades a causa del pan de centeno que se les da [...]». El Consejo de Guerra aseguraba que era consciente de los males padecidos en los presidios en general, y en el de Puigcerdà más particularmente, cuando se había representado muchas veces la necesidad de enviar medios para que las tropas pudiesen soportar el invierno vestidas, alimentadas y asistidas en los hospitales cuando enfermasen, pero a pesar de ser obligación de cristianos no se cumplía con ellas a menudo. Por otro lado, siempre se mostraron partidarios de mejorar las defensas de todo el Principado, no sólo las de Puigcerdà, y por ello antes quisieron saber cómo se hallaba la negociación del donativo voluntario solicitado para fortificaciones - es decir, que se había pagado, cuánto se debía, cuándo se esperaba cobrar-, para hacerse una idea más cabal de las cantidades necesarias, si bien se había decidido enviar 200.000 reales a Cataluña ya hacía cuatro meses y todavía no se habían remitido, en realidad, en septiembre de 1669 aun se reclamaba dicha cantidad con destino a Puigcerdà, Gerona y Figueras ${ }^{58}$.

El 29 de mayo el Consejo de Guerra volvía a reunirse al llegarle el día 23 un advertimiento de Mariana de Austria en el sentido de que tratasen sobre un informe recibido entonces, con fecha del 28 de marzo, sobre las necesidades

57 Noticia que ha traydo una persona que se embió al Rosellón de la parte de Puigcerdà, AGS, Estado, leg. 2688, enero de 1669. Consulta del CG, AGS, GA, leg. 2195, 28/VIII/1669.

58 Consulta del CG, AGS, GA, leg. 2195, 12/IX/1669. 
de las fortificaciones de Cataluña. Era un informe demoledor el remitido, todo lo parece indicar así, por la Real Audiencia, donde se aseguraba que más de la mitad de las obras de la plaza faltaban por concluir, ello sin contar con la necesidad urgente de artillería (de pequeño y mediano calibre para los bastiones) y dos morteros para arrojar bombas. Era igualmente necesario que uno o dos tercios de españoles vigilasen la Cerdaña, y no confiar en tropas de naciones - es decir, extra-peninsulares-, para guardar «las puertas de una plaza tan fronteriza y principal» ${ }^{59}$.

Cuando el duque de Sessa y Baena se hizo cargo del virreinato de Cataluña a inicios de 1670, llegaron una serie de informes a la Corte sobre el estado de las fortificaciones catalanas, uno realizado por el virrey saliente, Osuna, y otro por el propio Sessa. Iban a ser una buena piedra de toque sobre lo realmente realizado aquellos años en el caso de Puigcerdà. En cuanto a la artillería de la plaza, toda ella era de bronce y de reciente fabricación: constaba de cuatro medios cañones, doce cuartos de cañón y tres sacres. En comparación, en Castellfollit había sólo dos sacres y dos falconetes de bronce; y en Camprodón dos falconetes y dos mansfletres de bronce. Ya hemos visto que los franceses consideraban su parque artillero del Rosellón como muy limitado, pero el de las plazas hispanas reseñadas era limitadísimo. Y una cuestión no menos importante: en 1667 había apenas cuatrocientas balas de calibre de medio cañón y quinientas de calibre de cuarto de cañón. Unas cantidades irrisorias. En cuanto a las defensas de Puigcerdà, el duque de Osuna señaló:
... esta plaza es tal que necesita de infinito y así es menester que los medios ven- gan de Madrid pues los del donativo ${ }^{60}$, aunque se aplicasen todos a ella no bastarí- an, y es más necesario cuydar de su fortificación [h]oy habiéndome mandado $\mathrm{V}$. Magd. restituir los cinquenta y tres (sic) lugares de la adjacente Cerdaña que puse a la obediencia de V. Magd. los pocos días que estuvo rota la guerra, pues siendo nuestros cubrían a Puigcerdà y estando en poder de franceses es una amenaza per- petua a la plaza y más difícil el socorrerla si fuese necesario como sucedió quando la socorrí a[h]ora dos años pues a tener entonces aquellos lugares nuestros no fuera preciso exponerse a hacerlo a fuerça de armas.

Para colmo de males, ya en marzo de 1670, el duque de Sessa aseguraba que a causa de los fríos se había caído un gran trozo de muralla, una reparación que no quería dejar pasar una vez mejorase el tiempo, «y si en esta plaza no se perfeccionan las fortificaciones tendrá el mismo riesgo cada invierno» ${ }^{61}$.

59 Consultas del CG, AGS, GA, leg. 2194, 13-29/V/1669.

60 De 1663, prorrogado en 1667.

61 Relación de la artillería, armas y municiones..., existentes en Barcelona y las demás plazas del Principado, AGS, GA, leg. 2196, 13/XII/1669. Osuna a Mariana de Austria, ACA, CA, leg. 323, 8/XII/1669. Virrey Sessa a Mariana de Austria, ACA, CA, leg. 323, 22/III/1670. 
Por otro lado, el virrey aseguraba que con apenas 2.967 soldados de infantería sobre el papel - pues a dicha cifra había que restarle una tercera parte como «plazas muertas», es decir, supuestas-, y 780 oficiales en toda Cataluña, se había visto obligado a enviar de refuerzo a Puigcerdà medio centenar de infantes - además de dos compañías de caballería que ya estaban allá destacadas- , cuando según el propio Consejo de Guerra, una plaza como Puigcerdà, o Gerona, necesitaban del total de infantes destinados en el Principado para su guarnición, «para guarnecerla aun estando fortificada realmente ha menester más gente que la que [h]oy se halla en Cataluña [...]». El Consejo de Guerra reconocía no haber dinero para levar mil plazas en Castilla y Navarra para Cataluña, ni tampoco se enviaba el dinero solicitado para el arreglo de las fortificaciones del Principado ${ }^{62}$. Hubo de esperar Sessa cinco meses, hasta septiembre, para que le enviasen apenas 64.000 reales, y en tres partidas,

... para las fortificaciones de Puigçerdà con cuya cantidad se travaja en ellas desde fin de julio, y es tan poco caudal para lo que aquella plaza [h]a de consumir que solamente se podrá trabajar con él los pocos días que quedan de este mes, pues entrando el de octubre empiezan las aguas y los fríos en aquella montaña que no darán lugar más que tan solamente a hacer prevención de materiales para la primavera.

Sessa incluía copia de una carta del maestre de campo, don Manuel de Fonseca, gobernador de Camprodón, dirigida a él mismo del día 11 de septiembre en la que Fonseca explicaba que los franceses habían introducido aquellos días en Arlés y Prada veintidós piezas de artillería, grandes y pequeñas, setecientas cargas de municiones de todo tipo, así como multitud de bombas ${ }^{63}$.

A mediados de noviembre, el duque de Sessa, tras haber realizado un recorrido por las fortificaciones de la frontera (visitó Hostalric, Girona, Cadaqués y Roses, además de Puigcerdà), explicaba a Mariana de Austria las órdenes dictadas para la fortificación de la Cerdaña: había dejado mandado que se trabajase mientras el tiempo lo permitiera en la llamada tenaza del pozo de la nieve y en la media luna de la puerta de Llívia, «obras que ya están en buen estado y muy adelantadas». Cuando el frío impidiese trabajar con cal y canto, pues se sabía que el hielo no permitía ligar bien la cal, entonces se iría

62 Consulta del CA, ACA, CA, leg. 323, 22/V/1670. Consulta del CG, AGS, GA, leg. 2219, 21/V/1670.

63 Sessa a Mariana de Austria, AGS, GA, leg. 2219, 15/IX/1670. En abril de 1671 llegaron por mar, a Canet, treinta y séis piezas de artillería, veinticuatro de ellas de calibre de 24 libras de bala y las restantes de calibre 18; las artillerías fueron llevadas al castillo de Perpiñán, según informaba el virrey de Cataluña. Sessa a Mariana de Austria, AGS, GA, leg. 2246, 17/IV/1671. 
... cavando el fosso de dichas obras, y que con la misma tierra que se sacare dél se terraplene lo nezesario, y la demás que se sacare se lleve a los terraplenes más prezisos de la plaza; y que quando los fríos permitan a que se buelva a trabajar de cal y canto se cubran los valuartes de sancto Domingo y san Bartholomé, que están descubiertos hasta el mismo çimiento dominados de la Cruz de Roca, y sin foso, que se les haga foso artificial lebantando la contraescarpa desde el llano del terreno natural, que no se [h]a podido haçer por el pendiente de su situazión, con lo qual siendo estos dos puestos los que fixamente están expuestos al ataque y los más flacos y imperfectos con esta obra se vendrán a remediar sus faltas.

Es más, Sessa fue los suficientemente honesto para reconocer que las dimensiones de la plaza no ayudaban -en una época de dificultades-: Puigcerdà disponía de nueve baluartes y dos hornabeques, y a causa de este circuito de defensas necesitaba de dos mil hombres, para que podamos comparar, Rosas también necesitaba dos mil hombres con cinco baluartes, cinco revellines y cinco medias lunas. Camprodón necesitaba trescientos hombres, Seo de Urgel otros trescientos efectivos y Castellfollit la mitad, ciento cincuenta hombres. La conclusión era que Cataluña requería de 6.350 infantes efectivos solo para las guarniciones, y por entonces apenas si contaba con 2.160 , oficiales aparte ${ }^{64}$. Se trataba de un error de cálculo importante, toda vez que la intención era buena: las murallas de Puigcerdà, descritas por el conde de BussyRabutin en 165465 , no dejaban de ser de mediocre calidad, y la Monarquía Hispánica trató desesperadamente de corregir dicha contingencia. Pero falló la economía.

\section{CONCLUSIONES}

Como espero haber demostrado en las anteriores páginas, a pesar de la importancia manifiesta que tenía la plaza de Puigcerdà para la Monarquía Hispánica, especialmente después de la firma del tratado de paz de los Pirineos en 1659, y si bien se acudió con ciertas cantidades de dinero para su arreglo, el caso es que las fortificaciones de la capital de la Cerdaña jamás estuvieron en condiciones de una buena y perfecta defensa, según los cánones de la época, en el periodo analizado. Todavía a la altura de 1672-1673, cuando comenzó la guerra de Holanda, la fortificación no solo no estaba terminada (faltaban casi todas las defensas exteriores y algunos elementos importantes, como una tenaza), sino que carecía de artillería suficiente, así como de pertrechos de guerra y demás suministros.

64 Sessa a Mariana de Austria, AGS, GA, leg. 2220, 15/XI/1670. Consulta del CG, AGS, GA, leg. 2220, 26/XI/1670.

65 BUSSY-RABUTIN, 1731: 449-450. 
Por otro lado, aunque el virrey Sessa hizo un esfuerzo notorio al final de su mandato, la guarnición de la plaza tampoco estuvo nunca a la altura de lo necesario. De hecho, una de las características de Puigcerdà, su enorme circuito de murallas con nueve baluartes y dos hornabeques, se transformó en un gran problema, pues necesitaba de una cantidad de tropas de guarnición muy notoria, que el ejército de Cataluña, bajo mínimos aquellos años, no podía ofrecer. Tampoco llegaron las reclutas solicitadas. Y, con todo, la falta de inversiones por parte de Luis XIV en las defensas del Rosellón y el Conflent hasta 1668-1669 hizo que el duque de Osuna llegara a inquietar la nueva frontera en la campaña de 1667.

Así, la guerra de Devolución sirvió para advertir a los franceses que con una Puigcerdà en un mínimo estado defensivo, en realidad la frontera hispana se expandía hasta abarcar de nuevo toda la Cerdaña, incluida, pues, la francesa, y adelantaba posiciones hasta el Conflent, poniendo en peligro la plaza de Vilafranca. Posteriormente, la brillante campaña del virrey San Germán de 1674, con su conquista de Bellaguàrdia, que permitía atacar territorio galo por la Cerdaña y por el Ampurdán al mismo tiempo, hizo entender a Luis XIV que si quería utilizar el frente del Rosellón para desgastar a la Monarquía Hispánica, y evitar el envío de sus escasos medios de guerra a los frentes del norte de Italia y de Flandes, debía ser más activo en el mismo. Por ello, los franceses no sólo recuperaron Bellaguàrdia en 1675, sino que sitiaron y ocuparon Puigcerdà en 1678, último año de la guerra de Holanda. Que la devolviesen con sus defensas arrasadas por la paz de Nimega de dicho año demostró que Francia había aprendido la lección, y que ahora sería ella quien invadiese siempre Cataluña sin oposición tanto por el Ampurdán como por la Cerdaña. Es lo que ocurriría en las campañas de 1684 y, de nuevo, entre 1689 y 1697. Así, y en definitiva, los años transcurridos entre 1659 y 1672 fueron una oportunidad perdida de mejorar la posición estratégica hispánica en el Pirineo.

\section{Bibliografía}

Alonso Acero, Beatriz, Orán-Mazalquivir, 1589-1639: Una sociedad española en la frontera de Berbería, Madrid, CSIC, 2000.

Ayats, Alain, Les guerres de Josep de la Trinxeria, (1637-1694). La guerre du sel et les autres, Perpiñán, Trabucaire, 1997.

Ayats, Alain, Louis XIV et les Pyrénées catalanes de 1659 à 1681. Frontière politique et frontières militaires, Canet, Trabucaire, 2002.

Black, Jeremy, Beyond the Military Revolution. War in the Seventeenth-Century World, Houndmills/Nueva York, Palmgrave/MacMillan, 2011.

Bussy-Rabutin, Roger, Mémoires de messire Roger de Rabutin, comte de Bussy, vol. I, Amsterdam, S. Chatelain, 1731. 
Cénat, Jean-Philippe, Le roi stratège. Louis XIV et la direction de la guerre, 16611715, Rennes, PUR, 2010.

Espino, Antonio, «Cataluña o Portugal, 1659-1668. ¿Un falso dilema?», en A. Espino (ed.), Nuevas Fronteras de la Historia de la Guerra, Zaragoza, Pórtico libros, 2014: 93-120.

Espino, Antonio y Jané, Òscar, Guerra, frontera $i$ identitats, Catarroja-Barcelona, Afers, 2015.

Galcerán Vigué, Salvador, Dietari de la fidelíssima vila de Puigcerdà, Barcelona, Fundació Vives Casajuana, 1977.

Gozalbes Busto, Guillermo, Tetuán, Granada y la frontera del Estrecho: (siglos XV a XVII), Granada, Diputación, 2000.

Herrero Sánchez, Manuel, El acercamiento hispano-neerlandés (1648-1678), Madrid, CSIC, 2000.

Hess, Andrew C., The forgotten frontier. A history of the Sixteenth Century IberoAfrican Frontier, Chicago/Londres, University of Chicago Press, 1978.

Jané, Òscar, Catalunya i França al segle XVII. Identitats, contraidentitats $i$ ideologies a l'Època Moderna (1640-1700), Catarroja/Barcelona, Afers, 2006.

Jané, Òscar, La identitat de la frontera pirinenca. Efectes socials i politics al nord de Catalunya des de la creació de Montlluís (1677-1698), Gerona, Diputació, 2008.

Jané, Òscar, «Els exiliats polítics (agents d'una adaptació electiva) i la frontera amb França», en Òscar Jané (ed.), Del Tractat dels Pirineus (1659) a l'Europa del segle XXI: un model en construcció?, Barcelona, Generalitat de Catalunya, 2010: 265-273.

Lázaro Ávila, Carlos, Las fronteras de América y los Flandes indianos, Madrid, CSIC, 1997.

Lynn, John, Giant of the grand siècle, the french army, 1610-1715, Cambridge, CUP, 1998.

Marcet, Alicia, «La résistence catalane au landemain de l'annexion de 1659» en VV. AA., Mouvements populaires et conscience sociale, XVI-XIX siècles, París, Maloine, 1985.

Martí, M. Antònia y Espino, Antonio, Catalunya abans de la Guerra de Successió. Ambrosi Borsano $i$ la creació d'un nova frontera militar, 1659-1700, Catarroja/Barcelona, Afers, 2013.

Maura Gamazo, Gabriel, Vida y reinado de Carlos II, Madrid, Aguilar, 1990.

Moreira, Luís Miguel, «Desenhar a linha: a fronteira luso-galega do Alto Minho na cartografia militar portuguesa dos séculos XVII-XIX», Revista de Historiografía, 23 (2015): 47-65.

Porras Gil, Concepción, La organización defensiva española en los siglos XVI-XVII desde el río Eo hasta el Valle de Arán, Valladolid, Publicaciones de la Universidad de Valladolid, 1995.

Reichert, Rafal, Sobre las olas de un mar plateado. La política defensiva española y el financiamiento militar novohispano en la región del Gran Caribe, 1598-1700, Mérida, Yucatán, Centro Peninsular en Humanidades y Ciencias Sociales/UNAM, 2013. 
Rowlands, Guy, The dynastic state and the army under Louis XIV. Royal service and private interest, 1661-1701, Cambridge, CUP, 2002.

Sahlins, Peter, Fronteres i identitats: la formació d'Espanya i França a la Cerdanya, ss. XVII-XIX, Vic, Eumo, 1993.

Sanabre, Josep, La acción de Francia en Cataluña en la pugna por la hegemonía europea, Barcelona, Real Academia de Buenas Letras, 1956.

Sanabre, Josep, Resistència del Rosselló a incorporar-se a França, Perpiñán, Trabucaire, 1985.

Sanabre, Josep, El tractat dels Pirineus i la mutilació de Catalunya, Barcelona, Premsa catalana, 1989.

Sánchez Marcos, Fernando, Cataluña y el gobierno central tras la guerra de los Segadores, 1652-1679, Barcelona, Universitat de Barcelona, 1983.

Sánchez Rubio, Carlos, Sánchez Rubio, Rocío y Testón, Isabel, El Atlas Medici de Lorenzo Possi, 1687. Piante d'Estremadura e di Catalogna, Badajoz, 4 Gatos, 2014.

Serra, Eva, «El tractat dels Pirineus: Catalunya, un sol poble i dos destins», en Òscar Jané (ed.), Del Tractat dels Pirineus (1659) a l'Europa del segle XXI: un model en construcció?, Barcelona, Generalitat de Catalunya, 2010: 345-359.

Usunáriz Garayoa, Jesús M., «Soldados, sociedad y política en un reino de frontera: Navarra siglos XVI y XVII», Iura Vasconiae, 4 (2007): 285-325.

Valladares, Rafael, «El tratado de los Pirineos: una revisión historiográfica (18881998)», Espacio, tiempo y forma, 4/2 (Madrid, 1989): 111-123.

Valladares, Rafael, La rebelión de Portugal. Guerra, conflicto y poderes en la Monarquía Hispánica, Valladolid, Junta de Castilla y León, 1998.

Weber, David J., La frontera española en América del Norte, México D.F., FCE, 2000.

Recibido: 02/01/2016

Aprobado: 01/02/2017 